\title{
Assessment of silicon purification possibility by chemical vapor transport reaction with zinc sulfide
}

\author{
(C) Lyudmila Yu. Udoeva, ${ }^{+}$and Vladimir M. Chumarev** \\ Laboratory of non-ferrous metals pyrometallurgy. Institute of Metallurgy. Ural Branch of the Russian \\ Academy of Sciences. Amundsen St., 101. Yekaterinburg, 620016. Russia. \\ Phone: +7 (343)232-90-81. E-mail: lyuud@yandex.ru
}

\begin{abstract}
*Supervising author; ${ }^{+}$Corresponding author Keywords: vapor transport reaction, silicon sulfides, thermodynamic analysis, separation factors.
\end{abstract}

\begin{abstract}
The demand for renewable energy sources, including solar, is increasing every year, stimulating researchers to develop innovative technological solutions for obtaining material for photovoltaic modules solar silicon. The article discusses a new process for the vapor transport of silicon in the form of sulfide compounds, which can serve as the basis for a halogen-free technology for producing high-purity silicon for photovoltaic batteries. Considering the well-known properties of silicon di- and monosulfide, it is proposed to use zinc sulfide as a carrier reagent, the presence of which in the Si-ZnS system first provides silicon sulfidization with the formation of gaseous products $\mathrm{Zn}(\mathrm{g})$ and $\mathrm{SiS}(\mathrm{g})$, and then the reduction of monosulfide to elemental silicon. The possibility of a chemical vapor transport reaction of silicon with zinc sulfide at a temperature above $1000{ }^{\circ} \mathrm{C}$ and a $\mathrm{Si} / \mathrm{ZnS}$ ratio of 1 was justified by the method of the thermodynamic simulation of interactions in the $\mathrm{Si}-\mathrm{ZnS}$ system in the temperature range $500-1500{ }^{\circ} \mathrm{C}$. Based on the obtained equilibrium models of the interaction of zinc sulfide with technical silicon (grade $\mathrm{Kr} 2$ ), the separation coefficients of $(\alpha)$ silicon from impurity elements that affect the electrophysical properties of silicon, in particular, reduce the lifetime of excess charge carriers, are calculated. The selectivity of this transport reaction and the prospects for its use for refining metallurgical silicon are estimated. It has been shown that the use of the silicon transfer reaction of zinc sulfide, for example, at $1100{ }^{\circ} \mathrm{C}$, can provide deep purification of silicon from $\mathrm{Fe}, \mathrm{Ca}, \mathrm{Ti}, \mathrm{V}, \mathrm{Cr}, \mathrm{Mn}$ and $\mathrm{Cu}(\alpha \sim 108-1012)$, as well as $\mathrm{Mg}$ and $\mathrm{Al}(\alpha \sim 104-106)$. The process is less effective for removing P and B $(\alpha \sim 102)$ and is not applicable for alkali metals in the entire studied temperature range. It is theoretically possible to improve the refining indexes by lowering the reaction temperature, but the necessary sulfur concentration in the gas phase for the complete conversion of silicon to $\mathrm{SiS}(\mathrm{g})$ is achieved only above $1050-1100{ }^{\circ} \mathrm{C}$ due to thermal dissociation of $\mathrm{ZnS}$.
\end{abstract}

\section{References}

[1] V. Sidorovich. About the market of polycrystalline silicon - a key raw material for solar energy. 01.12.2018. (russian) http://renen.ru/on-the-market-of-polycrystalline-silicon-the-key-raw-material-forsolar-energy/

[2] E. Vartiainen, G. Masson, C. Breyer, D. Moser, E.R. Medina. Impact of weighted average cost of capital, capital expenditure, and other parameters on future utility-scale PV levelised cost of electricity. Progress in Photovoltaics. First published: 29 August 2019 https://doi.org/10.1002/pip.3189

[3] V.N. Yarkin, O.A. Kisarin, Yu.V. Rekov, I.F. Chervony. Silicon for solar energy: technology competition, market influence, development problems. Theory and Practice of Metallurgy. 2010. No.1-2. P.114-126. (russian)

[4] D.A. Toloknov, E.N. Selivanov, and R.I. Gulyaeva. The metal reduction thermodynamic simulate of sulfides. Part 2. Silicathermy. Butlerov Communications. 2012. Vol.29. No.1. P.89-92. ROI: jbc-02/12-29$1-89$

[5] G.G. Ninth, Yu.E. Elliev. Introduction to the theory of deep purification of substances. Moscow: Science. 1981. 320p. (russian)

[6] S.N. Borisov, M.G. Voronkov, E.Ya. Lukevits. Organosilicon derivatives of phosphorus and sulfur. Moscow: Chemistry. 1968. 292p. (russian)

[7] A guide to inorganic synthesis: in 6 vol. Vol.3. Ed. by. G. Brauer. Moscow: Mir. 1985. 392p. (russian)

[8] I.N. Odin, V.A. Ivanov, A.Yu. Petrovskii, V.F. Kozlovskii, R.R. Rezvanov. The Ptot-T-X diagram of the Si-S system. Russ. J. Inorg. Chem. 2000. Vol.45. No.3. P.479-481. (russian)

Kazan. The Republic of Tatarstan. Russia.

(C) Butlerov Communications. 2019. Vol.59. No.9. 
[9] A.V. Vanyukov, R.A. Isakova, V.P. Bystrov. Thermal dissociation of metal sulfides. Alma-Ata: "Science" of the Kazakh SSR. 1978. 272p. (russian)

[10] W.S. Schumb, W.J. Bernard. The Formation of Silicon Monosulfide. J. Amer. Soc. 1955. Vol.77. P.904-905.

[11] I.N. Odin. Ternary and reciprocal ternary systems containing cadmium, zinc, silicon, and bismuth chalcogenides: physicochemical analysis and characterization of alloys. Russ. J. Inorg. Chem. 1996. Vol.41. No.6. P.904-915. (russian)

[12] L.Yu. Udoeva, V.M. Chumarev, R.I. Gulyaeva. Kinetic analysis of gas-phase transfer of silicon by zinc sulfide. Prospective materials. 2019. No.9. P.5-14. (russian)

[13] H. Schäfer. Chemische Transportreactionen. Weinheim: Verlag Chemie. 1960. 278p. 